\title{
Contamination of the cold water distribution system of health care facilities by Legionella pneumophila: Do we know the true dimension?
}

M Arvand (mardjan.arvand@hlpug.hessen.de) ${ }^{1}$, K Jungkind $^{2}$, A Hack ${ }^{1}$

1. Hesse State Health Office, Centre for Health Protection, Dillenburg, Germany

2. Communal Health Office of the Wetteraukreis, Friedberg, Germany

Citation style for this article:

Arvand $\mathrm{M}$, Jungkind K, Hack A. Contamination of the cold water distribution system of health care facilities by Legionella pneumophila: Do we know the true dimension?. Euro Surveill. 2011;16(16):pii=19844. Available online: http://www.eurosurveillance.org/ViewArticle.aspx?Articleld=19844

Article published on 21 April 2011

German water guidelines do not recommend routine assessment of cold water for Legionella in healthcare facilities, except if the water temperature at distal sites exceeds $25{ }^{\circ} \mathrm{C}$. This study evaluates Legionella contamination in cold and warm water supplies of healthcare facilities in Hesse, Germany, and analyses the relationship between cold water temperature and Legionella contamination. Samples were collected from four facilities, with cases of healthcare-associated Legionnaires' disease or notable contamination of their water supply. Fifty-nine samples were from central lines and 625 from distal sites, comprising 316 cold and 309 warm water samples. Legionella was isolated from central lines in two facilities and from distal sites in four facilities. $17 \%$ of all central and $32 \%$ of all distal samples were contaminated. At distal sites, cold water samples were more frequently contaminated with Legionella ( $40 \%$ vs $23 \%$, p <0.001) and with higher concentrations of Legionella $(\geq 1,000$ colony-forming unit/100 $\mathrm{ml})(16 \%$ vs $6 \%$, p<0.001) than warm water samples. There was no clear correlation between the cold water temperature at sampling time and the contamination rate. $35 \%$ of cold water samples under 20 ${ }^{\circ} \mathrm{C}$ at collection were contaminated. Our data highlight the importance of assessing the cold water supply of healthcare facilities for Legionella in the context of an intensified analysis.

\section{Introduction}

Legionnaires' disease (LD) is an important cause of hospital-acquired pneumonia [1]. Potable water was recognised as the major environmental source of healthcare-associated LD (hca-LD) in the early $1980 \mathrm{~s}$ [1]. After this discovery, almost all cases of hca-LD have been linked to potable water [2-5]. For example, in the United Kingdom, 19 of 20 hospital LD outbreaks from 1980 to 1992 could be attributed to the water distribution system (WDS) [6]. Microaspiration is the major mode of transmission of hca-LD [7]. Because the clinical manifestations are non-specific, and specialised laboratory testing is required, LD is easily underdiagnosed $[1,8]$.
Routine testing for Legionella of environmental water samples by culture has emerged as an effective strategy for prevention of hca-LD. Guidelines mandating routine monitoring of Legionella contamination of the WDS in hospitals and other healthcare facilities have been implemented in many European countries, including Spain, France, the United Kingdom, and Germany $[1,9]$. In contrast, the Centers for Disease Control and Prevention (CDC) recommends environmental cultures only when cases of hca-LD are discovered [10], an approach which remains controversial, taking into account that a specific diagnostic for LD is not routinely performed in many laboratories. For example, in the United States of America (USA) only $19 \%$ of the hospitals that participated in the CDC National Nosocomial Surveillance System did routinely provide Legionella testing of patients at high risk for developing hca-LD [11]. In Germany, the Federal Environment Agency (Umweltbundesamt) and the German National Public Health Institute (Robert Koch Institute) recommend periodical analysis of the WDS of hospitals, nursing homes and other healthcare facilities [12]. If a moderate to high level contamination is detected, i.e. at Legionella concentration of $\geq 1,000$ colony-forming unit $(\mathrm{cfu} / 100 \mathrm{ml}$, an intensified analysis with additional sampling points according to the guidelines of the German Technical and Scientific Association for Gas and Water (DVGW) is recommended $[12,13]$.

Legionella can grow and amplify at temperatures between $25{ }^{\circ} \mathrm{C}$ and $45{ }^{\circ} \mathrm{C}$ with an optimum between $32{ }^{\circ} \mathrm{C}$ and $42{ }^{\circ} \mathrm{C}$. Legionella pneumophila is able to withstand temperatures of $50{ }^{\circ} \mathrm{C}$ for several hours, but does not multiply at temperatures below $20^{\circ} \mathrm{C}$ [9]. Therefore, keeping water temperature outside the range for Legionella, i.e. $\geq 55^{\circ} \mathrm{C}$ and $<20^{\circ} \mathrm{C}$ is an effective prevention and control measure for both warm and cold water systems. In Germany, which has a temperate climate, the temperature of cold water at entry to a building is usually below $20{ }^{\circ} \mathrm{C}$. The German guidelines do not recommend routine assessment of cold water for Legionella contamination. In the context of intensified analysis, assessment of cold water is rec- 
ommended if the water temperature at the distal site exceeds $25{ }^{\circ} \mathrm{C}$ [12].

The Hesse State Health Office (HSHO) is a federal institution in charge of surveillance, prevention, and control of LD in Hesse, a state with six million inhabitants located in west-central Germany. The diagnostic laboratories of HSHO offer a broad spectrum of chemical and microbiological analysis for water samples. Our institution is usually consulted by the communal health authorities when cases of hca-LD are detected in a healthcare facility or if routine environmental cultures reveal a notable contamination by Legionella species. We here present the results of the evaluation of the WDS of four healthcare facilities, which had contacted us for assistance to control and prevent Legionella contamination of their WDS. Two cases of hca-LD had been diagnosed in one facility, an acute care hospital with a solid organ transplantation unit, whereas a moderate to high Legionella contamination had been detected upon routine assessment in the other facilities, which included a rehabilitation centre and two nursing homes. A multidisciplinary team was sent to each facility in order to determine the extent of contamination of the WDS, to assess the contamination of cold and warm WDS independently and to investigate a possible correlation between the water temperature at sampling time and the extent of Legionella contamination.

\section{Methods}

\section{Healthcare facilities}

The healthcare facilities included in this study consisted of an acute care hospital specialised in thoracic surgery and solid organ transplantation (260 beds), a rehabilitation centre with cardiologic, orthopaedic and psychosomatic departments (183 beds), a nursing home for physically disabled individuals ( 47 beds), and a nursing home for elderly people (220 beds). These facilities had been requested by the Communal Health Office to conduct intensified Legionella monitoring because high Legionella concentrations had been detected during periodical assessment and/or cases of hca-LP had been reported. Each facility was visited by a team of specialists of the Communal Health Office and the HSHO several times (four to six times) between March 2009 and August 2010. The results presented in this study are derived from the analysis of samples that were obtained at the first visit of our team to the facilities between March 2009 and February 2010.

\section{Sampling procedure}

Sampling points were selected by the team of specialists in cooperation with the technical teams of the facilities to obtain a comprehensive sample of cold and warm water for intensified analysis, in accordance with the recommendations of DVGW [13]. Fifty-nine samples were obtained from central lines (cold and hot-water tanks, return lines) of all facilities, including facility A (one warm sample), facility B (four cold samples), facility C (24 warm, 25 cold samples), and facility D (three warm, two cold samples). Six hundred and twenty-five samples were obtained from distal sites (467 showerheads, 155 taps, one pond and two spring fountains) of the facilities, comprising facility A (10 warm, 12 cold samples), facility B (15 warm, 16 cold samples), facility C (252 warm, 256 cold samples), and facility D (32 warm, 32 cold samples). Cold and warm water were generally sampled in parallel at distal sites. The temperature was documented and samples of approximately $200 \mathrm{ml}$ were collected at central sites after discarding $3 \mathrm{~L}$ of cold or $3 \mathrm{~L}$ of warm water, and at distal sites after discarding $3 \mathrm{~L}$ of cold or $5 \mathrm{~L}$ of warm water, according to recommendations of the Federal Environment Agency [12]. It is noteworthy that the latter sampling method differs slightly from the European guidelines, which recommend samples of one litre in volume to be collected immediately after the opening of the water outlet [14].

\section{Laboratory investigation}

Legionella culture was performed on GVPC agar (Oxoid) according to recommendations of the Federal Environment Agency [15]. Two aliquots of $0.5 \mathrm{ml}$ water were inoculated directly to GVPC agar and $100 \mathrm{ml}$ was filtered through a $0.45 \mu \mathrm{m}$ cellulose-nitrate membrane. The filter was overlaid with $20 \mathrm{ml} 0.2 \mathrm{M} \mathrm{HCl}-\mathrm{KCl}[\mathrm{pH} 2.2]$ and incubated for 4-5 min. The buffer was discarded, the filter was rinsed with $10 \mathrm{ml}$ sterile water and placed on GVPC agar. The cultures were incubated at $37^{\circ} \mathrm{C}$ in a humidified atmosphere and examined after three, five, seven and 10 days. The detection limit of our method was one $\mathrm{cfu} / 100 \mathrm{ml}$.

\section{TABLE 1}

Legionella contamination rate in cold and warm water samples obtained from four healthcare facilities, Hesse, Germany, March 2009-February $2010(\mathrm{n}=684)$

\begin{tabular}{|c|c|c|c|c|}
\hline Sample collection site & Sample type & $\begin{array}{c}\text { Legionella positive } \\
\text { n (\%) }\end{array}$ & $\begin{array}{c}\text { Legionella negative } \\
\text { n (\%) }\end{array}$ & $\begin{array}{c}\text { Total } \\
n\end{array}$ \\
\hline \multirow[t]{3}{*}{ Central line } & All & $10(17)$ & $49(83)$ & 59 \\
\hline & Cold water & $1(3)$ & $30(97)$ & 31 \\
\hline & Warm water & $9(32)$ & $19(68)$ & 28 \\
\hline \multirow[t]{3}{*}{ Distal } & All & $197(32)$ & $428(68)$ & 625 \\
\hline & Cold water & $125(40)$ & $191(60)$ & 316 \\
\hline & Warm water & $72(23)$ & $237(77)$ & 309 \\
\hline
\end{tabular}


Identification was conducted by performing subcultures of at least three colonies per sample on BCYE agar (Oxoid) and sheep-blood agar. Legionella isolates grew on BCYE agar but not on sheep-blood agar. Serotyping was performed with a latex agglutination kit (Legionella Latex Test, Oxoid), which allows the identification of Legionella pneumophila serogroup 1, L. pneumophila serogroups 2-14, and non-pneumophila Legionella species.

\section{Statistical analysis}

Statistical analysis was performed with Stata, Version 11.1, 2009 (StataCorp LP, Texas, USA). Chi square test

\section{FIGURE 1}

Legionella contamination in cold and warm water collected at distal sampling sites in four healthcare facilities, Hesse, Germany, between March 2009 and February $2010(n=625)$

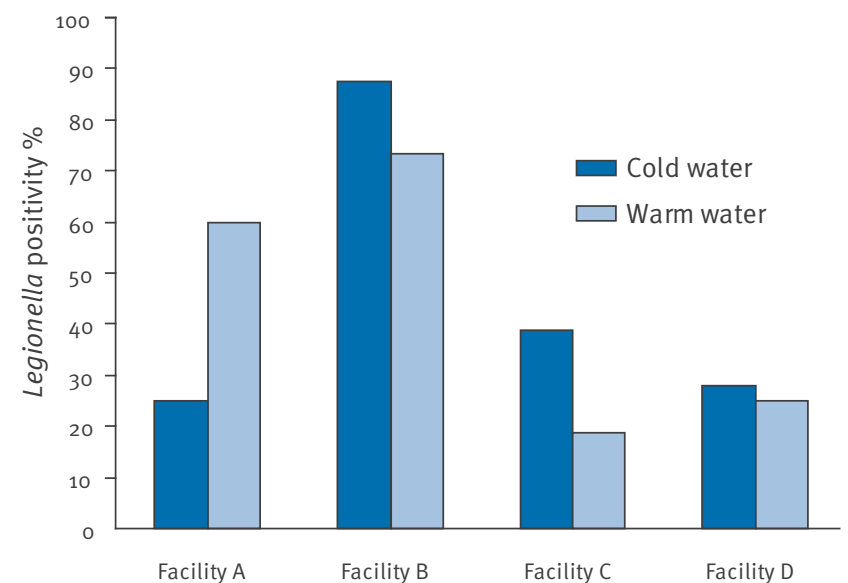

or Fisher exact test were used for analyzing qualitative data. Results were considered statistically significant when the $P$ value was $<0.05$.

\section{Results}

Contamination rate in cold and warm water Fifty-nine samples were collected at central lines, including 28 warm (temperature range: $46-75^{\circ} \mathrm{C}$ ) and 31 cold (temperature range: $7-14^{\circ} \mathrm{C}$ ) water samples. A total of 10 of 59 central samples were contaminated, comprising nine of 28 warm and one of 31 cold water samples (Table 1). Hence, among the central samples, warm water was more frequently contaminated with Legionella than cold water ( $\mathrm{p}<0.001)$.

Six hundred and twenty-five distal samples were analysed, including 309 warm (temperature range: $32-70{ }^{\circ} \mathrm{C}$ ) and 316 cold (temperature range: $7-29{ }^{\circ} \mathrm{C}$ ) water samples. A total of 197 of 625 (32\%) distal samples were contaminated. Legionella was detected in 125 of $316(40 \%)$ cold water samples and 72 of $309(23 \%)$ warm water samples (Table 1). Thus, among the distal samples, cold water was more frequently contaminated with Legionella than warm water ( $p<0.001)$.

We next evaluated the results at the level of individual facilities. The temperature of cold and warm water differed slightly between the facilities. At distal sites, cold water temperatures of $8-25^{\circ} \mathrm{C}$ (facility A), $9-24^{\circ} \mathrm{C}$ (facility B), $7-28^{\circ} \mathrm{C}$ (facility C), and $13-29^{\circ} \mathrm{C}$ (facility D) and warm water temperatures of $40-64^{\circ} \mathrm{C}$ (facility $\mathrm{A}$ ), $36-65^{\circ} \mathrm{C}$ (facility B), $32-70^{\circ} \mathrm{C}$ (facility C), and $50-66^{\circ} \mathrm{C}$ (facility D) were measured at sampling time. Legionella

\section{TABLE 2}

Legionella contamination in distal cold and warm water samples collected in four healthcare facilities, Hesse, Germany, March 2009-February $2010(n=625)$

\begin{tabular}{|l|c|c|c|c|c|c|}
\hline & \multicolumn{3}{|c|}{ Cold water } & \multicolumn{3}{c|}{ Warm water } \\
\hline Healthcare facility & Total & Legionella positive & Legionella $\geq 1,000$ cfu/100 $\mathbf{m l}$ & Total & Legionella positive & Legionella $\geq 1,000$ cfu/100 $\mathbf{m l}$ \\
\hline Facility A $(\mathrm{n}=\mathbf{2 2})$ & $\mathbf{1 2}$ & $\mathbf{3}$ & $\mathbf{0}$ & $\mathbf{1 0}$ & 6 & 0 \\
\hline Facility B $(\mathrm{n}=31)$ & $\mathbf{1 6}$ & 14 & 8 & $\mathbf{1 5}$ & 11 & 5 \\
\hline Facility C $(\mathrm{n}=508)$ & $\mathbf{2 5 6}$ & 99 & 37 & $\mathbf{2 5 2}$ & 47 & 15 \\
\hline Facility D $(\mathrm{n}=64)$ & $\mathbf{3 2}$ & 9 & $\mathbf{3 2}$ & $\mathbf{3 2}$ & 0 \\
\hline
\end{tabular}

\section{TABLE 3}

Legionella concentration and temperature range of cold and warm water collected at distal sites in four healthcare facilities, Hesse, Germany, March 2009-February $2010(n=625)$

\begin{tabular}{|l|c|c|c|c|c|c|c|}
\hline \multirow{2}{*}{$\begin{array}{l}\text { Legionella concentration } \\
(\mathrm{cfu} / 100 \mathrm{ml})\end{array}$} & \multicolumn{4}{|c|}{ Cold water } & \multicolumn{3}{c|}{ Warm water } \\
\cline { 2 - 8 } & $\begin{array}{c}\text { Temperature range } \\
\left({ }^{\circ} \mathrm{C}\right)\end{array}$ & $\mathrm{n}$ & $\%$ & $\begin{array}{c}\text { Temperature range } \\
\left({ }^{\circ} \mathrm{C}\right)\end{array}$ & $\mathrm{n}$ & $\%$ & $\mathrm{P}$ value \\
\hline$<1$ & $7-28$ & 191 & 60 & $38-70$ & 237 & 77 & $<0.001$ \\
\hline $1-99$ & $8-25$ & 13 & 4 & $39-65$ & 18 & 6 & 0.361 \\
\hline $100-999$ & $11-27$ & 63 & 20 & $37-64$ & 34 & 11 & 0.003 \\
\hline$\geq 1,000$ & $11-29$ & 49 & 16 & $32-62$ & 20 & 6 & $<0.001$ \\
\hline Total & $\mathbf{7 - 2 9}$ & $\mathbf{3 1 6}$ & $\mathbf{1 0 0}$ & $\mathbf{3 2 - 7 0}$ & $\mathbf{3 0 9}$ & $\mathbf{1 0 0}$ & \\
\hline
\end{tabular}

a The P values were calculated by comparing the proportion of cold water samples displaying a distinct Legionella concentration among all cold water samples with the proportion of warm water samples with the similar Legionella concentration among all warm water samples. 
contamination was detected in distal cold and warm water of all facilities. The overall positivity rate was nine of $22(41 \%), 25$ of $31(81 \%), 146$ of $508(29 \%)$, and 17 of $64(27 \%)$ in distal water of the facilities A, B, C, and $D$, respectively. Remarkably, contamination was more frequently detected in cold water than in warm water in three facilities (Figure 1). The contamination

\section{FIGURE 2}

Relationship between the temperature of distal water at sampling time and Legionella contamination, Hesse, Germany, March 2009-February $2010(n=625)$
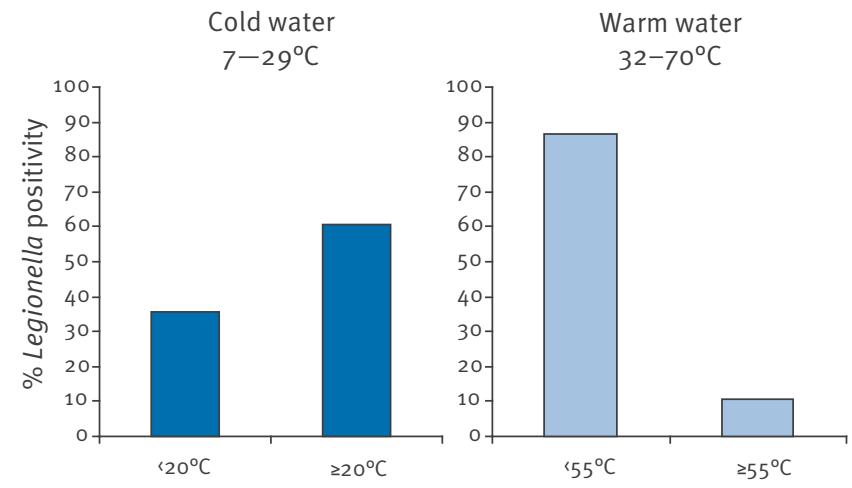

\section{FIGURE 3}

Relationship between contamination rate of distal water and the threshold temperature for cold and warm water, Hesse, Germany, March 2009-February $2010(n=625)$
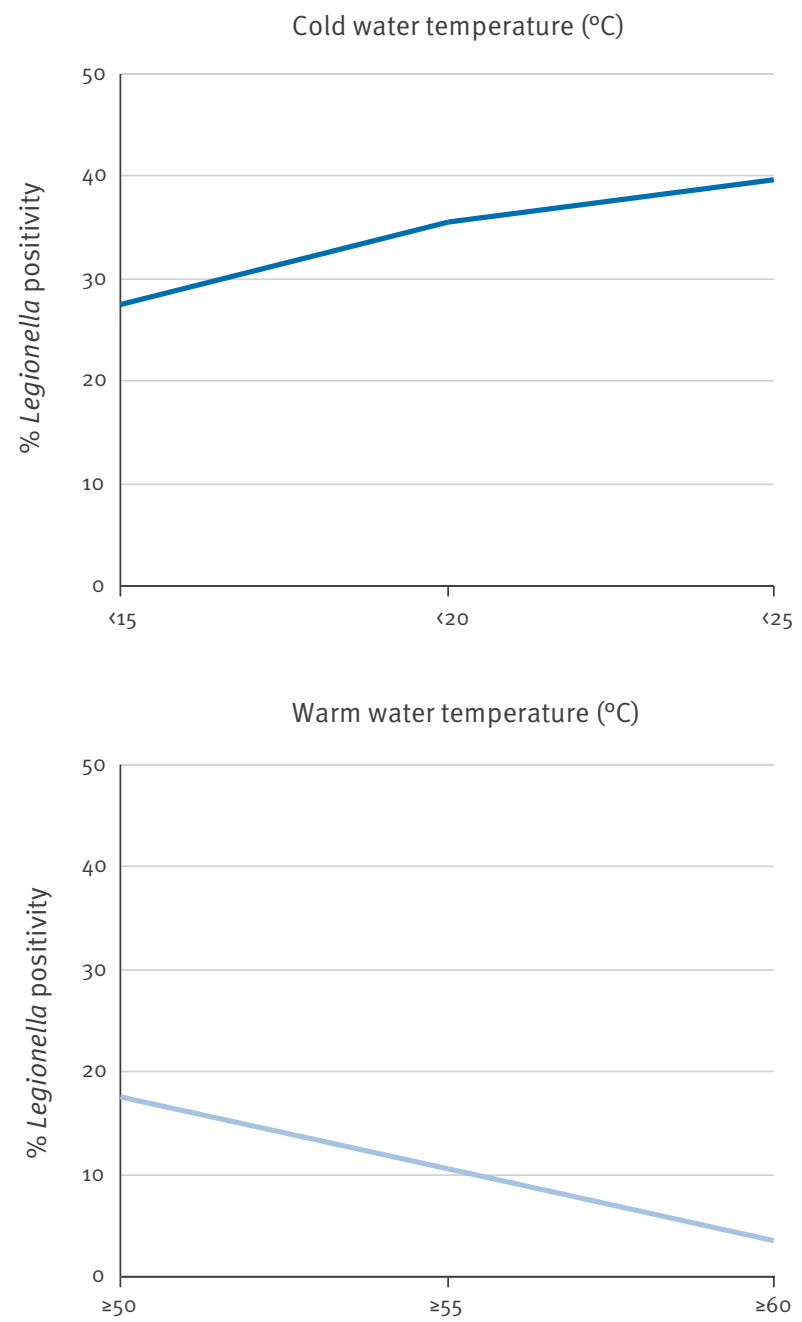

rate of cold and warm water in the facilities A, B, C, and D were $25 \%$ versus $60 \%, 88 \%$ versus $73 \%$, 39 versus $19 \%$, and 28 versus $25 \%$, respectively (Table 2 ).

\section{Legionella species and serogroups detected}

Serological differentiation of the Legionella isolates from the WDS revealed $L$. pneumophila serogroup 1 in facility $A, C$, and $D, L$. pneumophila serogroup 2-14 in facility $\mathrm{B}$, and non-pneumophila Legionella spp. in facility $A$ and C. L. pneumophila serogroup 1 was also isolated from the bronchoalveolar lavage fluid of the index patient with hca-LD in facility C. The L. pneumophila isolates obtained from the patient and the water supply displayed the same geno- and serotype, as determined by multilocus sequence typing (MLST) and monoclonal antibody serotyping, which were performed at the Legionella Reference Laboratory, University of Dresden, Germany.

\section{Legionella concentration in \\ cold and warm water}

Of 316 distal cold water samples analysed, $60 \%$ were tested negative for Legionella, $4 \%$ revealed minimal contamination (colony count 1-99 cfu/100 ml), $20 \%$ moderate contamination $(100-999 \mathrm{cfu} / 100 \mathrm{ml})$ and $16 \%$ high contamination ( $\geq 1,000 \mathrm{cfu} / 100 \mathrm{ml})$. Of 309 distal warm water samples analysed, $77 \%$ were negative, $6 \%$ displayed minimal contamination, $11 \%$ moderate contamination, and $6 \%$ high contamination (Table 3). In detail, a total of 69 samples comprising 49 cold and 20 warm water samples revealed a high Legionella concentration ( $\geq 1,000 \mathrm{cfu} / 100 \mathrm{ml})$. Thirty three of $49(67 \%)$ highly contaminated cold water samples displayed a temperature of $220^{\circ} \mathrm{C}$ at collection time, whereas three of $20(15 \%)$ highly contaminated warm water samples displayed a temperature of $\geq 55^{\circ} \mathrm{C}$ at sampling time. Together, cold water samples were more frequently contaminated with higher Legionella concentrations compared to warm water samples. The difference between cold and warm water was significant in all categories except for minimal contamination (Table 3).

We next evaluated the prevalence of high Legionella concentrations, i.e. $\geq 1,000 \mathrm{cfu} / 100 \mathrm{ml}$, in cold and warm water of different facilities. As shown in Table 2, a high grade contamination was detected in three of four facilities. Cold water samples were more frequently contaminated with high Legionella concentrations than warm water samples in three of four facilities (Table 2).

\section{Relationship between temperature and Legionella contamination}

We next examined the relationship between the temperature of distal water at sampling time and Legionella contamination. Cold and warm water samples were assigned to four groups, cold water $<20^{\circ} \mathrm{C}$, cold water $\geq 20^{\circ} \mathrm{C}$, warm water $\angle 55^{\circ} \mathrm{C}$, and warm water $\geq 55^{\circ} \mathrm{C}$ and the contamination rate was calculated for each group. The positivity rate was 94 of $265(35 \%), 31$ of $51(61 \%)$, 45 of $52(87 \%)$, and 27 of $257(11 \%)$ in the latter groups, respectively (Figure 2). It is noteworthy that $35 \%$ of 
cold water samples that displayed an optimal temperature in terms of Legionella prevention at sampling time, that is $<20^{\circ} \mathrm{C}$, were contaminated. In contrast, only $11 \%$ of warm water samples that displayed an optimal temperature in terms of Legionella prevention, that is $\geq 55$ ${ }^{\circ} \mathrm{C}$, were contaminated. Outside the temperature range of Legionella growth, there was significantly less contamination in warm water than contamination in cold water ( $p<0.001)$.

We further examined whether we may find a threshold temperature that would allow a reliable discrimination between contaminated and non-contaminated distal water. The threshold temperatures of $15^{\circ} \mathrm{C}, 20{ }^{\circ} \mathrm{C}$ and $25^{\circ} \mathrm{C}$ were tested for cold water, and $50{ }^{\circ} \mathrm{C}, 55^{\circ} \mathrm{C}$, and $60{ }^{\circ} \mathrm{C}$ for warm water. The contamination rate of samples beyond the selected temperature was calculated separately. As shown in Figure 3, 43 of 156 (28\%) of water samples that were below $15{ }^{\circ} \mathrm{C}$ at sampling time, which is below the lower limit $\left(20^{\circ} \mathrm{C}\right)$ of the range of Legionella growth, were contaminated by Legionella. This suggests that measuring cold water temperature at sampling does not allow the defining of a reliable temperature threshold, below which cold water would be considered free from Legionella contamination.

\section{Discussion}

We here present the results of assessment of the water supplies of four healthcare facilities in Germany. The investigation was initiated because cases of hca-LD were diagnosed in one facility (Facility C) or because periodical analysis had suggested a severe contamination of the WDS with Legionella (facilities A, B, and D). The contamination rate of distal water samples was $41 \%, 81 \%, 29 \%$ and $27 \%$ in the four facilities examined. The very high rate in some cases ( $81 \%$ ) was not entirely unexpected in light of the circumstances that had led to the enrolment of the facilities in this study.

We found higher contamination rates and higher Legionella concentrations in cold water samples than in warm water samples collected from distal sites in three facilities (Figure 1, Table 2). Legionellosis has been traditionally associated with inadequately heated warm water [1]. There is a common belief that only the warm water supply may serve as a source of infection. Nonetheless, previous studies have shown that the cold water supply of healthcare facilities may be heavily contaminated with Legionella species [16]. Other investigators have reported cases of hca-LD that were attributed to contamination of the cold water supply. Hoebe et al. [17] reported two cases of fatal LD in a rehabilitation centre linked to the cold water supply. Johansson et al. [18] described a case of hca-LD in Sweden that was clearly linked to the cold WDS. Graman et al. [19] reported a case of hca-LD that was traced back to a contaminated ice machine. Our data show that the cold water supply of healthcare facilities may be even more heavily contaminated by Legionella species than the warm water supply. We found Legionella concentrations of up to $10,000 \mathrm{cfu} / 100 \mathrm{ml}$ in distal cold water samples (data not shown). Different factors may have contributed to this interesting phenomenon. It is possible that a thermal disinfection of warm WDS was performed shortly prior to our visit to the facility. This could have resulted in a temporal suppression of Legionella in the warm water supply. Another possible explanation is a "warming-up" of cold water, which may occur after long intervals of stasis or when the cold and warm water pipes are closely fitted in the same shaft and run together over a long distance without appropriate insulation. The warming-up effect may not be detectable at the time of sampling, which is usually during daytime on a weekday. In the latter case, hot water flushing of warm water tubes may even have a paradoxical effect on contamination of the cold WDS by aggravating the warming-up effect.

Analysis of the temperature of distal samples revealed that only 16 of $316(5 \%)$ cold water samples displayed a temperature of $25{ }^{\circ} \mathrm{C}$ or more at sampling time, which is the threshold temperature recommended by the German water guidelines for assessment of cold water [12]. We therefore tested other threshold temperatures. We found that 94 of 265 (35\%) and 43 of 156 $(28 \%)$ of the distal cold water samples that displayed a temperature of $<20{ }^{\circ} \mathrm{C}$ and $\angle 15^{\circ} \mathrm{C}$ at sampling time were contaminated (Figure 3). Taken together, our data show that high Legionella concentrations may be found in cold water samples displaying a temperature of as low as $11^{\circ} \mathrm{C}$ at sampling time, whereas no or very low Legionella concentrations may be associated with cold water temperatures of up to $28{ }^{\circ} \mathrm{C}$ at sampling time (Table 3). Hence, our data suggest that there is no reliable correlation between the temperature of cold water at sampling time and the extent of Legionella contamination. A possible explanation for this incoherence is that the temperature at sampling time, which is usually a busy time on a working day, is not representative of the temperatures that the sampled water has undergone prior to sampling.

After release of the results of our investigation, the infection control precautions were reassessed in all facilities and additional decontamination measures and prevention strategies were initiated for the warm and cold WDS. The results of the intervention activities were controlled by follow-up investigation.

In conclusion, our data suggest that the cold water supply of healthcare facilities may be heavily contaminated with Legionella species. We did not find a reliable correlation between cold water temperature at sampling time and Legionella contamination rate or concentration. If we had restricted our analysis to cold water samples that displayed at least $25^{\circ} \mathrm{C}$ at sampling time, we would have missed many cases of severe contamination. Our results highlight the importance of assessment of cold water in the context of intensified analysis of the water supply of healthcare facilities. 


\section{Acknowledgements}

We would like to thank the technical team of the Hygiene and Infection Control laboratory of the HSHO for excellent technical assistance and Jens Fitzenberger for statistical support.

\section{References}

1. Sabria M, Yu VL. Hospital-acquired legionellosis: solutions for a preventable infection. Lancet Infect Dis. 2002;2(6):368-73.

2. Garcia-Nunez M, Sopena N, Ragull S, Pedro-Botet ML, Morera J, Sabria M. Persistence of Legionella in hospital water supplies and nosocomial Legionnaires' disease. FEMS Immunol Med Microbiol. 2008;52(2):202-6.

3. Ozerol IH, Bayraktar M, Cizmeci Z, Durmaz R, Akbas E, Yildirim Z, et al. Legionnaire's disease: a nosocomial outbreak in Turkey. J Hosp Infect. 2006;62(1):50-7.

4. Sabria M, Garcia-Nunez M, Pedro-Botet ML, Sopena N, Gimeno JM, Reynaga E, et al. Presence and chromosomal subtyping of Legionella species in potable water systems in 20 hospitals of Catalonia, Spain. Infect Control Hosp Epidemiol. 2001;22(11):673-6.

5. Kohler JR, Maiwald M, Luck PC, Helbig JH, Hingst V, Sonntag HG. Detecting legionellosis by unselected culture of respiratory tract secretions and developing links to hospital water strains. J Hosp Infect. 1999;41(4):301-11.

6. Joseph CA, Watson JM, Harrison TG, Bartlett CL. Nosocomial Legionnaires' disease in England and Wales, 1980-92. Epidemiol Infect. 1994;112(2):329-45.

7. Blatt SP, Parkinson MD, Pace E, Hoffman P, Dolan D, Lauderdale P, et al. Nosocomial Legionnaires' disease: aspiration as a primary mode of disease acquisition. Am J Med. 1993;95(1):16-22.

8. von Baum H, Ewig S, Marre R, Suttorp N, Gonschior S, Welte T, et al. Community-acquired Legionella pneumonia: new insights from the German competence network for community acquired pneumonia. Clin Infect Dis. 2008;46(9):1356-64.

9. World Health Organization (WHO). Legionella and the prevention of legionellosis. Geneva:WHO; 2007. Available from: http://www.who.int/water_sanitation_health/emerging/ legionella.pdf

10. Tablan OC, Anderson LJ, Besser R, Bridges C, Hajjeh R. Guidelines for preventing health-care-associated pneumonia, 2003: recommendations of CDC and the Healthcare Infection Control Practices Advisory Committee. MMWR Recomm Rep. 2004;53(RR-3):1-36.

11. Fiore AE, Butler JC, Emori TG, Gaynes RP. A survey of methods used to detect nosocomial legionellosis among participants in the National Nosocomial Infections Surveillance System. Infect Control Hosp Epidemiol. 1999;20(6):412-6.

12. Umweltbundesamt. Periodische Untersuchung auf Legionellen in zentralen Erwärmungsanlagen der Hausinstallation nach $\S 3$ Nr. 2 Buchstabe c TrinkwV 2001, aus denen Wasser für die Öffentlichkeit bereitgestellt wird [Periodical analysis for Legionella in water heating and distributions systems]. Bundesgesundheitsbl. 2006;7:697-700. German.

13. Deutsche Vereinigung des Gas- und Wasserfaches e.V. (DVGW). Bonn: Trinkwassererwärmungs- und Trinkwasserleitungsanlagen; Technische Maßnahmen zur Verminderung des Legionellenwachstums [Association of gas and water technologies, Technical meausures to prevent Legionella contamination of water distribution systems]. DVGW Arbeitsblatt W 551, Ausgabe 4/2004. German.

14. Joseph C, Lee J, Van Wijngaarden J, Drasar V, Castellani Pastoris M. European Working Group for Legionella Infections. European Guidelines for Control and Prevention of Travel Associated Legionnaires' Disease. London: Public Health Laboratory Service; 2002. Available from: http://www.hpa.org. uk/web/HPAwebFile/HPAweb_C/1274093149925.

15. Umweltbundesamt. Nachweis von Legionellen in Trinkwasser und Badebeckenwasser Empfehlung des Umweltbundesamtes nach Anhörung der Trink- und Badewasserkommission des Umweltbundesamtes. [Detection of Legionella in drinking water and bathing water]. Bundesgesundheitsbl. 2000;43:9115. German.

16. Wagenvoort JH, Sijstermans ML. From legionnaire to guerrilla combatant: suppression of Legionella pneumophila in a hospital cold water supply. J Hosp Infect. 2004;58(2):162-3.

17. Hoebe CJ, Cluitmans JJ, Wagenvoort JH. Two fatal cases of nosocomial Legionella pneumophila pneumonia associated with a contaminated cold water supply. Eur J Clin Microbiol Infect Dis. 1998;17(10):740.
18. Johansson PJ, Andersson K, Wiebe T, Schalen C, Bernander S. Nosocomial transmission of Legionella pneumophila to a child from a hospital's cold-water supply. Scand J Infect Dis. 2006;38(11-12):1023-7.

19. Graman PS, Quinlan GA, Rank JA. Nosocomial legionellosis traced to a contaminated ice machine. Infect Control Hosp Epidemiol. 1997;18(9):637-40. 